\title{
Assessment of PM1 number concentration with respect to traffic flow and thermal environment in a residential underground garage
}

\author{
Yu Zhao ${ }^{1,3}$, Xiaocheng Song ${ }^{2, *}$ and Jianing Zhao ${ }^{3}$ \\ ${ }^{1}$ Institute of Building Energy, School of Civil Engineering, Faculty of Infrastructure Engineering, Dalian University of Technology, Dalian \\ 116024, China \\ ${ }^{2}$ Civil and Architectural Engineering College, Dalian University, Dalian 116622, China \\ ${ }^{3}$ School of Municipal \& Environmental Engineering, Harbin Institute of Technology, Harbin 150090, China \\ Received: 12/11/2017, Accepted: 05/02/2018, Available online: 21/06/2018 \\ *to whom all correspondence should be addressed: e-mail: sxciscc@163.com
}

\begin{abstract}
Particles with aerodynamic diameters $<1 \mu \mathrm{m}$ (PM1) damage human health more severely than do coarse particles. In this study, PM1 number concentration, traffic flow, temperature and relative humidity in both a residential underground garage and at the entrance/exit, wind velocity at the entrance/exit were measured between May and June 2012 in Harbin, China. Pearson and partial correlations were employed to quantify the relationship between PM1 number concentration, traffic flow, and the thermal environment. The results show that mean PM1 number concentration in the garage during the measurement was 21,905 particles $\mathrm{cm}^{-3}$, which was approximately 1.54 times higher than the outdoor environment. Mean traffic flow, with a value of 0.2 vehicles $\min ^{-1}$, may be the most important factor impacting PM1 pollution levels in the garage. The effects of air temperature inside the garage and wind velocity at the entrance/exit on PM1 pollution may be stronger compared with other environmental parameters. An inverse relationship between air temperature and PM1 number concentration was observed and decrease in wind velocity at the entrance/exit resulted in increased PM1 number concentration. This study provides fundamental reference data for PM1 number concentration levels in a residential underground garage.
\end{abstract}

Keywords: underground garage, PM1 exposure, air quality, traffic flow, thermal environment, correlation analysis

\section{Introduction}

With rapid development and urbanization in China, environmental problems have become increasingly serious. Particles, especially submicron particles, are one of the main pollutants that can threaten human health severely. Several studies have confirmed that the exposure to such particles may cause health problems. Increases in asthma medication use and symptoms were found in association with particulate air pollution (Pekkanen et al., 1997; Von et al., 2002; Nicolai et al., 2003; Braniš et al., 2009). Some chronic diseases, such as myocardial infarction and lung cancer, may also be caused by longterm exposure to particles (Peters et al., 2004; Pui et al., 2014; Chen et al., 2015). There are strong indications that the adverse health effects of particles may be attributed not to particle mass concentration but to particle number concentration (Penttinen et al., 2001; Franck et al., 2011; Weichenthal, 2012; Buonanno et al., 2013). For this reason, research on particle number concentration has attracted a great deal of interest in recent years.

Compared with ground space in urban areas, underground garages are potentially hazard zones for human health because of their enclosed structures and high number of vehicle passages. Some studies on underground spaces such as tunnels, subways, and underground shopping areas have demonstrated that the levels of fine and ultrafine particulate pollution are several times higher than the corresponding values in some of the busiest streets (Pfeifer et al., 1999; Sitzmann et al., 1999; Gouriou et al., 2004; Kristensson et al., 2004; Zhu et al., 2014). In China, to reduce operating costs, the majority of residential underground garages turn off mechanical ventilation systems all year. Thus, natural ventilation is the only ventilation throughout the year in most residential underground garages. Particulate pollution in those residential underground garages is even worse than in underground garages with mechanical ventilation systems in Europe and North America. Insufficient or malfunctional ventilation allows contaminated air to accumulate, and particle concentrations to increase. The persistent accumulation of particulate pollutant over years may threaten the health of car owners, security guards, and workers in garages. With the anticipated increase in traffic intensity, the pollution level in underground spaces is only expected to worsen. Thus, research into underground garages is of major importance.

The mechanism of traffic-related particle formation is very complex. In the air, after emission, a particle undergoes many transformations, affected by a variety of nonlinear and interactive processes, which change the concentration and physicochemical properties (Bukowiecki et al., 2002; Burtscher, 2005; Kittelson et al., 2006; Maricq, 2007). 
Several reports have focused on particle formation and dilution processes. The results have shown that these processes were strongly influenced by background conditions (Janhäll et al., 2012). For constant engine operation conditions, a decrease in ambient air temperature is associated with increased supersaturation ratio, which results in an increase in nuclei-mode particles (Hinds, 1982). Charron and Harrison, (2003) found that ultrafine particles showed an inverse association with air temperature. Some reports have shown that there was some relationship between the number concentration of particles emitted from road vehicles, temperature, and wind velocity (McGregor et al., 2003; Gidhagen et al., 2006; Wang and Gao, 2011). As particulate pollution at the outdoor environment becomes severe, especially in China, outdoor particles are one of the most important particle sources in traffic-related environments, which have been demonstrated by recent studies (Tan and Tay, 2008). Nevertheless, the majority of recent research has been performed in ground spaces. Studies on air pollution in underground garages have thus far been very limited. Carbon monoxide (CO) has been used as an important indicator of air pollution level in garages (Chow et al., 1996; Xue and Ho, 2000). The results have shown that $\mathrm{CO}$ concentration in garages is expectedly high, and variation of $\mathrm{CO}$ concentration is correlated with vehicle conditions and thermal environmental parameters, such as ambient temperature. Few published reports have described particle pollution levels in underground garages ( $\mathrm{Li}$ and Xiang, 2013; Obaidullah et al., 2013). There are still large uncertainties surrounding the effects of traffic flow and the thermal environment on particle dilution in underground garages. Thus, research on particle pollution in underground garages warrants greater attention.

The objective of this study was to evaluate PM1 number concentration levels, traffic flow, and the thermal environment in a residential underground garage. Some research results have demonstrated that the majority of particles emitted by gasoline vehicles are less than $1 \mu \mathrm{m}$ in size (Maricq et al., 1999). The movement and variation of particles show the characteristics of submicron particles. In this study, because of the limitations of the measurement instruments, only PM1 number concentration was adopted as the pollutant indicator. The effects of certain key factors, including traffic flow and the thermal environment, on PM1 pollution in the garage were also evaluated in the study.

\section{Measurement site, parameters, and protocols}

Field measurements were conducted in a residential underground garage in Harbin, China. The garage is surrounded by more than 10 multistoried residential buildings. The distances from the main road to the entrance and exit of the garage are approximately 200 and $100 \mathrm{~m}$, respectively. A public green space is located above the garage, and there is little traffic outside except for vehicles driving in and out of the garage. The garage covers
4,000 $\mathrm{m}^{2}$ and has two stories. Table 1 shows detailed information of the garage. The measurement site and surrounding environments are shown in Fig. 1.

In China, the majority of residential underground garages are solely ventilated by natural wind throughout the year to save energy. In Harbin, natural wind is strongest during spring (May to June) compared with other seasons, based on our previous study (Zhao et al., 2017). Ventilation inside the garage is significant, and the effects of the thermal environment on particle number concentration could not easily be weakened by traffic flow or other factors. Thus, the period of 7 May to 10 June 2012 was selected as the measurement period inside the garage. During the measurement period, both the entrance and exit were continuously open. The mechanical ventilation system in the garage was turned off. The measurement period was characterized by dry weather conditions. Ventilation in the underground garage was dominated by wind pressure during measurements. (The sampling time each day was from 7:00 to 19:00 on weekdays and from 8:00 to 20:00 on weekends.

For comparison, hourly meteorological parameters from a meteorological station on the roof of the School of Municipal \& Environmental Engineering, Harbin Institute of Technology were employed to reflect weather conditions during the garage measurement period. The meteorological station was less than $1 \mathrm{~km}$ from the garage, and an aerial image of the meteorological station and garage can be found in Fig. 1a. The station was approximately $20 \mathrm{~m}$ above the ground. The data logging interval for temperature and relative humidity was 1 hour, and wind velocity and direction were logged every 3 hours. Meanwhile, continuous measurement over two days was also performed in the surrounding outdoor environment near the underground garage. Because only one condensation particle counter was available for the study, measurement in the underground garage and in the outdoor environment could not proceed simultaneously. Measurement in the outdoor environment was conducted during 21-22 June 2012 (weekdays). The weather during 21-22 June 2012 was sunny. The test time was the same as the sampling time for weekdays in the underground garage, from 7:00 to 19:00. Outdoor particle concentration is dominated by meteorological conditions (Gouriou et al., 2004) in cases without a significant particle source nearby, such as the study area. As shown in Fig. 7, meteorological conditions were nearly the same from 7 May to 10 June during garage measurement and on 21-22 June during measurement of the surrounding outdoor environment. Thus, the outdoor particle concentration should be approximately the same between the period of 7 May to 10 June and 21-22 June. Although measurement in the garage and the outdoor environment could not proceed simultaneously, comparison of nanoparticle pollution levels between the garage and the surrounding outdoor environment was appropriate in this study. 
Table 1. Detailed information of the garage.

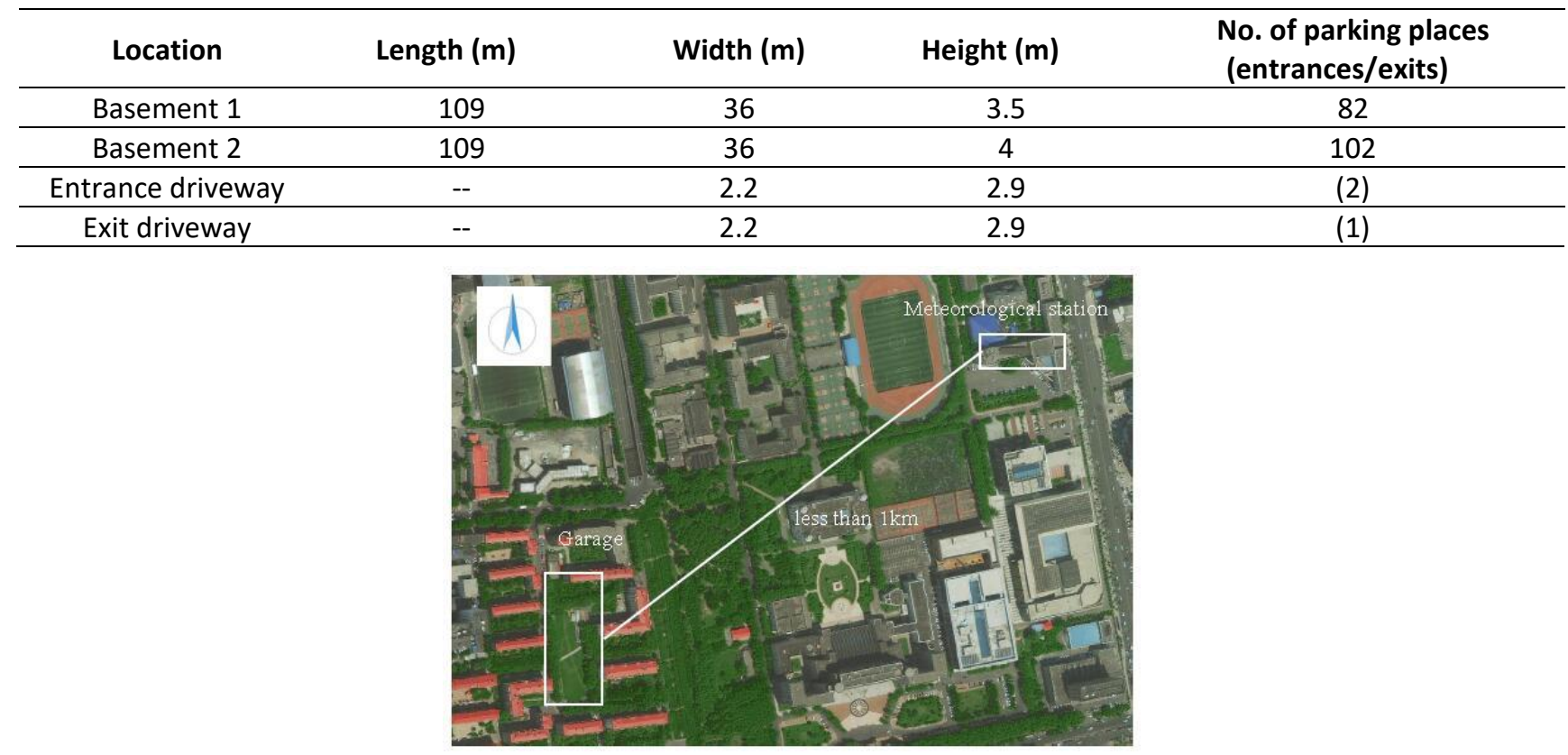

a) Aerial images of residential garage and meteorological station

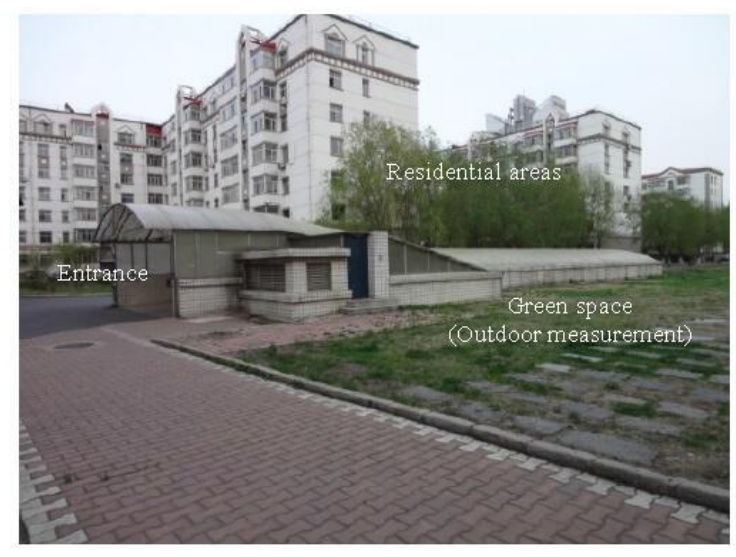

b) Surrounding environment above the garage

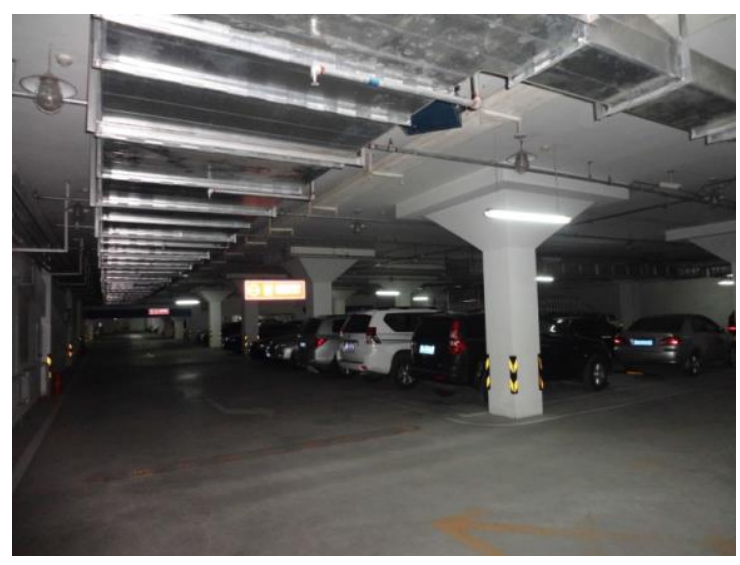

c) Environment inside the garage

Figure 1. Measurement garage, surrounding residential area, and a meteorological station near the garage in Harbin, China 
The variables measured in the residential garage were traffic flow, PM1 number concentration, ambient temperature, and relative humidity. At the entrance/exit of the garage, wind velocity, temperature, and relative humidity were measured. Hourly traffic flow in the garage was recorded manually, and the number of vehicles driving into and out of the garage per hour was summed for analysis. PM1 number concentration was also measured at the outdoor environment.

Spatial distribution measurement was employed for nanoparticle number concentration, temperature, and relative humidity in the garage. The sample protocol was determined based on the large volume of the garage indicated by the data in Table 1, which means the variables were unevenly distributed in the garage. Mean values of the variables at different stations throughout the garage were more representative of the levels of PM1 pollution. Twelve stations were set up to measure PM1 number concentration, ambient temperature, and relative humidity. These stations were located throughout the garage, from entrance driveway to exit driveway. Each measuring station stood $1.5 \mathrm{~m}$ above the garage floor. The location of each station is shown in Fig. 2. Time interval between adjacent stations in Fig. 1 when sampling particle number concentration was $5 \mathrm{~min}$. The cycle for measuring all 12 stations once was 1 hour (Zhao and Zhao, 2013).
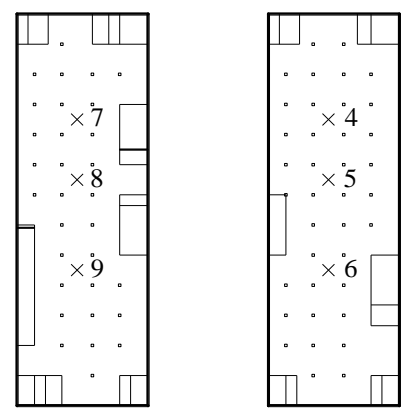

Plan of Basement 1 Plan of Basement 2

a)Measurement stations in basements 1 and 2

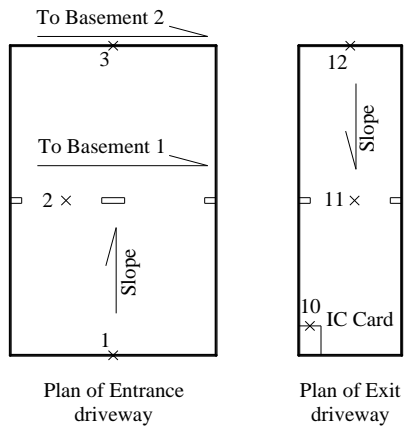

b) Measurement stations in entrance/exit driveway

Figure 2. PM1 number concentrations measurement stations in the garage.

Temperature, relative humidity, and wind velocity at entrance/exit were measured continuously near the top of entrance/exit door without disturbing traffic (Fig. 3). The arithmetic mean value during each 5-min continual measurement was recorded for all variables at the entrance/exit. One sampling point in the middle of the outdoor space above the garage was established for continuous measurements. This sampling point stood 1.5 $\mathrm{m}$ above the ground. To keep in accordance with the amount of measured data in the garage, the arithmetic mean nanoparticle number concentration of each 5-min continual measurement was recorded.

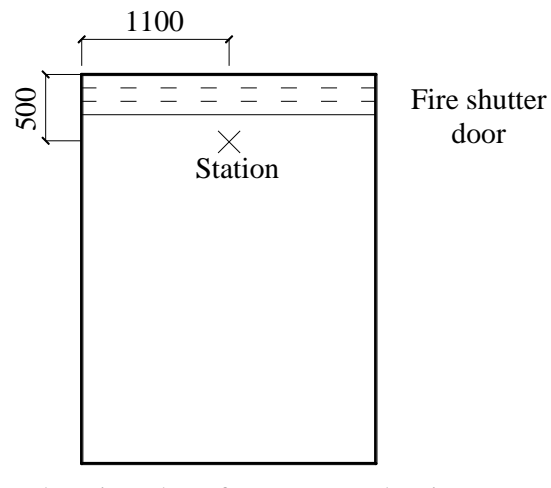

Elevation plan of Entrance and Exit

Figure 3. Measurement station in entrance and exit crosssection (lengths are in millimeters)

A condensation particle counter was used in this study (TSI, Model 3007) to measure particle number concentrations in real time, in the size range of 0.01 to $1 \mu \mathrm{m}$ up to $10^{5}$ particles $\mathrm{cm}^{-3}$ with a precision of $\pm 20 \%$. Ambient temperature and relative humidity in the garage were collected using temperature/relative humidity data loggers (onset $\mathrm{HOBO}$ ), with a temperature range of -20 to $+70^{\circ} \mathrm{C}$ and a relative humidity range of $5 \%$ to $95 \%$, accuracy of \pm $0.35^{\circ} \mathrm{C}$ from $0^{\circ}$ to $50^{\circ} \mathrm{C}$, and $\pm 2.5 \%$ from $10 \%$ to $90 \%$. The multifunction measuring instrument (Testo, Model 435) used for measurement of temperature, relative humidity, and wind velocity at entrance/exit was a real-time device with low-speed velocity probes and thermal probes with integrated temperature and air humidity measurement for analyzing ventilation and indoor air quality. The wind velocity probe was unidirectional; wind direction was not measured in this study. The range and accuracy were, respectively, $0-20 \mathrm{~m} \mathrm{~s}^{-1}$ and $0.03 \mathrm{~m} \mathrm{~s}^{-1}+4 \%$ of mean velocity for velocity, -20 to $+70^{\circ} \mathrm{C}$ and $0.3^{\circ} \mathrm{C}$ for temperature, and 0 to $+100 \%$ and $2 \%$ for relative humidity ( +2 to $+98 \%$ relative humidity) for relative humidity. All instruments were calibrated following the directions given by the manufacturers before measurements.

\section{Data analysis}

The relationships between each pair of variables were analyzed using Pearson correlation (Vogt and Johnson, 2012). The main influential factors on nanoparticle number concentration were indicated by larger positive or negative correlation coefficients. Because traffic flow and environmental conditions influence the variation of PM1 number concentration simultaneously, partial correlations (Guilford and Fruchter, 1973) to find correlation between two variables after removing the effects of other variables were also calculated to identify the impact of each 
parameter on nanoparticle number concentration after controlling for other parameters. To eliminate random error in this study, the data used for analysis were hourly averaged values.

Data used in correlation analysis included three aspects: (i) hourly traffic flow, (ii) PM1 number concentration, and (iii)

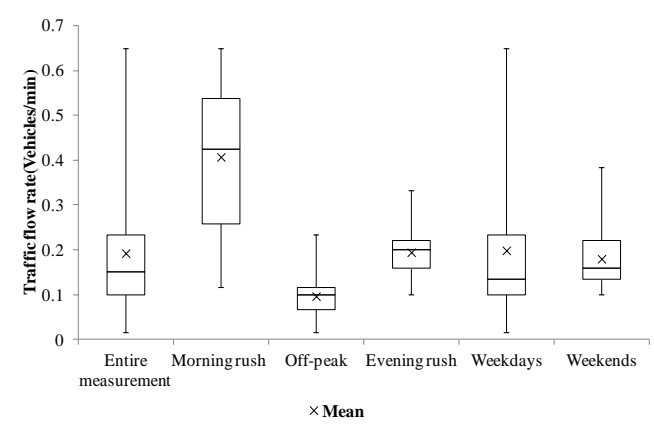

a) Traffic flow rate

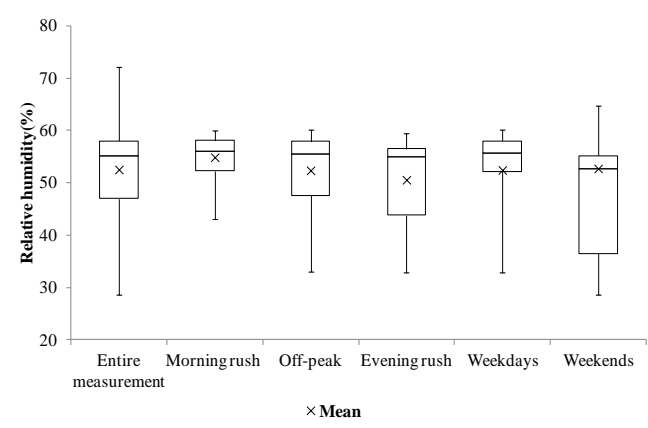

c) Relative humidity in parking garage

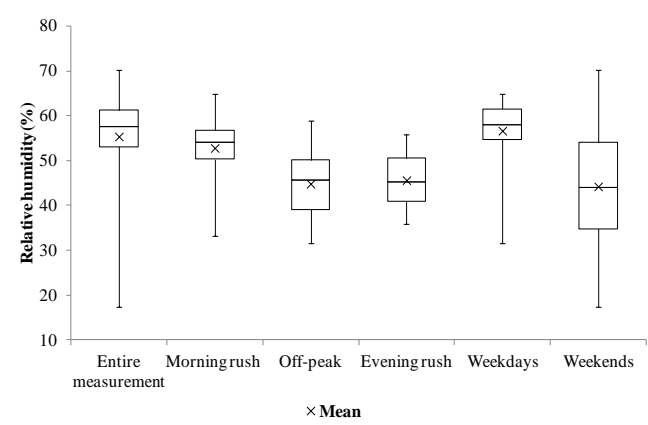

e) Relative humidity at entrance/exit environmental parameters including temperature, relative humidity, and wind velocity in the garage and at the entrance/exit. PM1 number concentration was the dependent variable; traffic flow and the thermal environment were the independent variables. The software SPSS Statistics 17.0 was applied for correlation analysis.

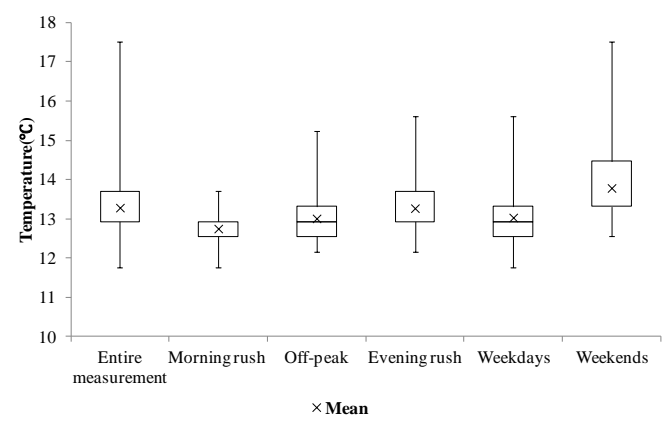

b) Temperature in parking garage

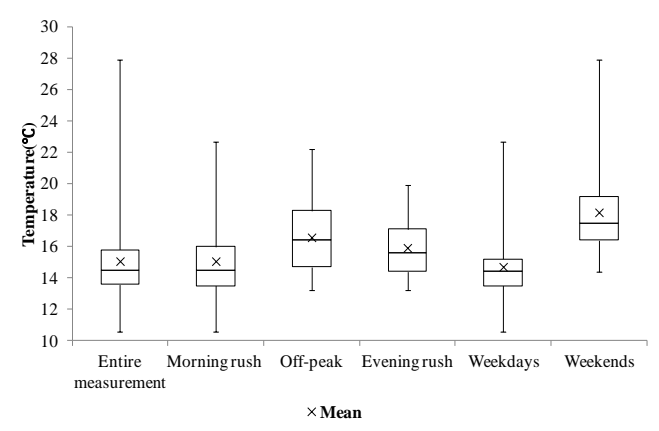

d) Temperature at entrance/exit

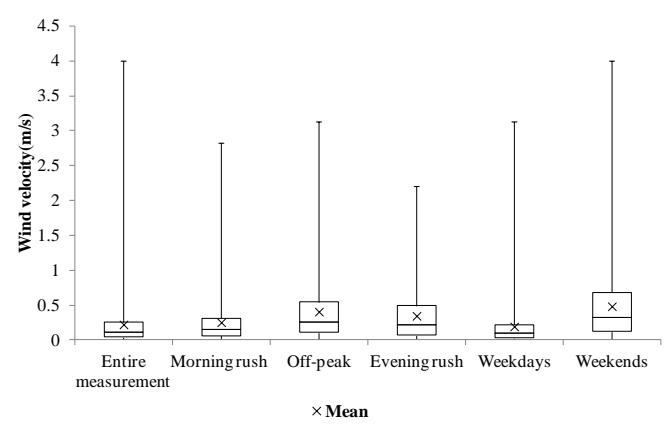

f) Wind velocity at entrance/exit

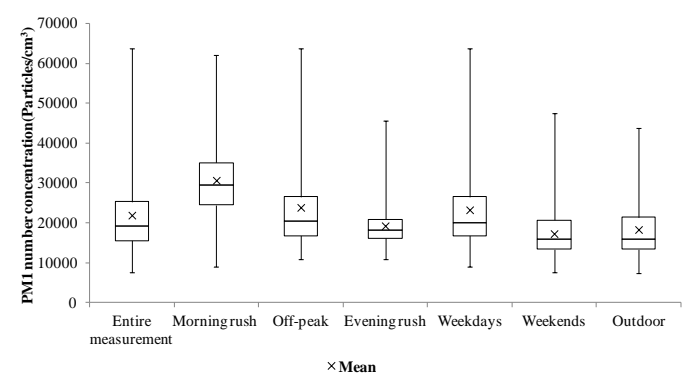

g) PM1 number concentration

Figure 4. Detailed results of measurement data analysis for the measured period. The values of data from small to large shown in the box-plot represent minimum, percentile 25, median, percentile 75 and maximum, respectively. 


\section{Results and Discussion}

The data set for the entire measurement period of the garage was divided into five parts: (i) data measured on weekdays (from Monday to Friday), (ii) data measured during morning rush hour on weekdays (7:00-10:00), (iii) data measured during evening rush hour on weekdays (16:00-19:00); (iv) data measured during off-peak hours on weekdays (10:00-16:00), and (v) data measured on weekends (Saturday and Sunday). Detailed results of the measurement data analysis are presented in Fig. 4

\subsection{Traffic flow rate}

As shown in Fig. 4a in the Supporting Information shows, the distribution of traffic flow rate in the garage was uniform other than on weekdays, with an overall median of 0.13 vehicles $\mathrm{min}^{-1}$, only $67 \%$ of the mean of 0.2 vehicles $\mathrm{min}^{-1}$. Mean data for morning rush hour and evening rush hour were four times and two times higher than off-peak traffic flow rates, respectively. Fig. 5 shows mean traffic flow per minute in the garage. The measurement data indicated that the regularity of traffic flow rate in the residential underground garage, especially on weekdays, was quite stable with two peaks during morning (8:00) and afternoon rush hour (18:00). The morning peak traffic flow (8:00) on weekdays was nearly 0.53 vehicles $\mathrm{min}^{-1}$ and was about 2.5 times higher than the evening peak traffic flow $\left(18: 00,0.22\right.$ vehicles $\left.\mathrm{min}^{-1}\right)$. The difference in traffic flow between morning (9:00, 0.3 vehicles $\mathrm{min}^{-1}$ ) and evening rush hour $\left(17: 00,0.17\right.$ vehicles $\left.\mathrm{min}^{-1}\right)$ on weekends was less notable.

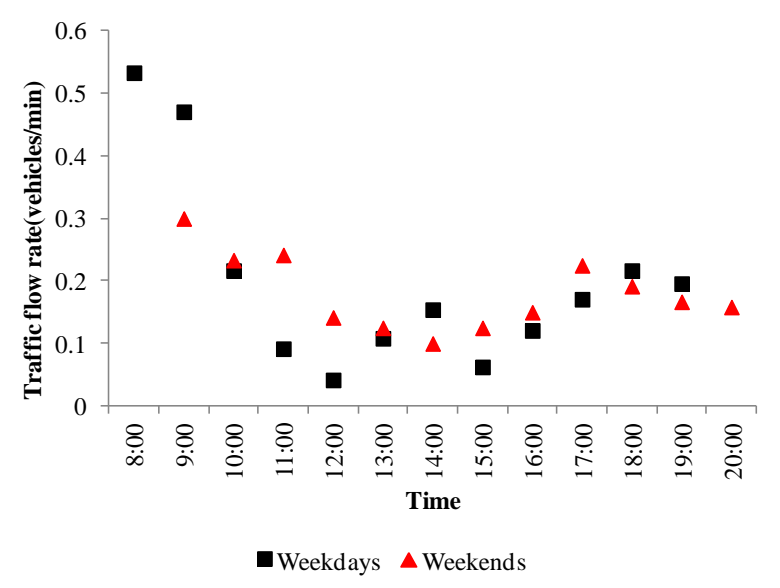

Figure 5. Hourly traffic flow rate in the garage; traffic flow rate was calculated by dividing each average hourly traffic flows by 60 minutes.

The traffic flow pattern in this study was similar to those of some research on road-traffic particles (Jamriska et al.,
2008; Zhang et al., 2012). Comparison between traffic flow rate in this study and that reported by Jamriska et al. (2008) is listed in Table 2. This comparison showed that the traffic flow rate in the residential underground garage was almost $1 \%$ of that measured in streets. This finding may indicate that the influence of traffic flow rate on PM1 number concentration was much less than that in the street.

Table 2. Comparison of traffic flow rate between this study, Tora St. and Ipswich Rd.

\begin{tabular}{ccc}
\hline Location & $\begin{array}{c}\text { Mean traffic flow } \\
\text { rate } \\
\text { (vehicles/min) }\end{array}$ & $\begin{array}{c}\text { Median traffic } \\
\text { flow rate } \\
\text { (vehicles/min) }\end{array}$ \\
\hline This study & 0.19 & 0.15 \\
\hline Tora St. & 24.6 & 27 \\
\hline Ipswich Rd. & 29.4 & 29.4 \\
\hline
\end{tabular}

4.2 Indoor thermal environment

Fig. $4 \mathrm{~b}$ and $\mathrm{c}$ show that the temperature and relative humidity distributions in the garage were both remarkably uniform, with less than $0.5^{\circ} \mathrm{C}$ and $5 \%$ difference between the mean and median temperature and relative humidity, respectively. Hourly mean temperature, relative humidity, and wind velocity in the garage and at the entrance/exit are presented in Fig. 6 . Hourly mean temperature in the garage during measurement stabilized around $13^{\circ} \mathrm{C}$. Relative humidity in the garage frequently fluctuated compared with temperature. Nevertheless, the maximum fluctuation of hourly averaged relative humidity was only $10 \%$. Therefore, the environment in the garage was very homeostatic during measurement.

Temperature and relative humidity at the entrance/exit were mainly affected by the outdoor environment. The distributions of temperature and relative humidity during the entire measurement period at the entrance/exit were also uniform, with a median of $14.5^{\circ} \mathrm{C}$ and a mean $15.1^{\circ} \mathrm{C}$ for temperature, and a median of $57.6 \%$ and a mean of $55.4 \%$ for relative humidity. Fig. $6 c$ and $d$ show that an inverse relationship was observed between temperature and relative humidity.

Wind velocity at the entrance/exit showed a random distribution with a median of $0.11 \mathrm{~m} \mathrm{~s}^{-1}$ and a mean of 0.22 $\mathrm{m} \mathrm{s}^{-1}$. Wind velocity at the entrance/exit of the garage was solely dominated by natural wind outside because the mechanical ventilation system was turned off during the measurement period. Because natural wind is typically randomly distributed, variation of wind velocity at the entrance/exit of the garage should also be disorderly. Thus, the hourly mean wind velocity shown in Fig. $6 e$ and $f$ tended to have no apparent regularity during the measurement period. 


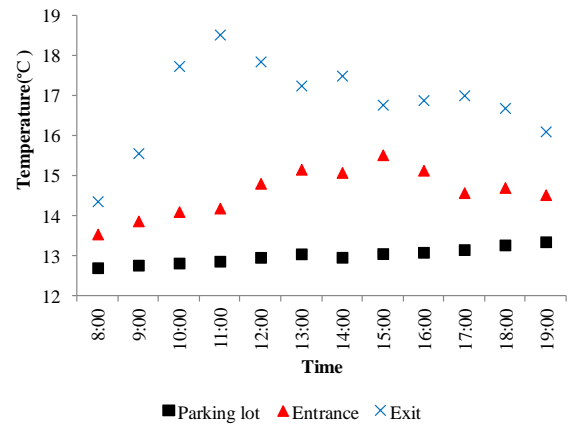

a) Indoor temperature during weekdays

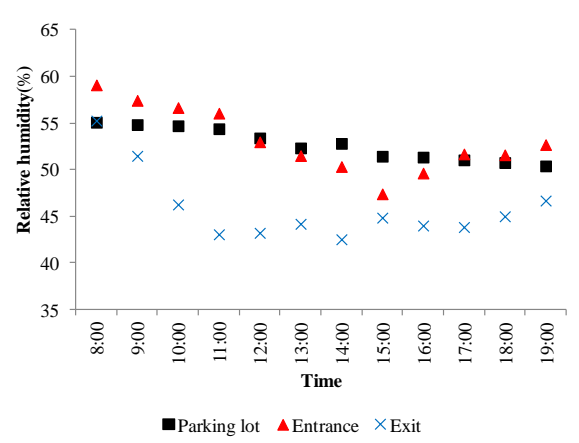

c) Indoor relative humidity on weekdays

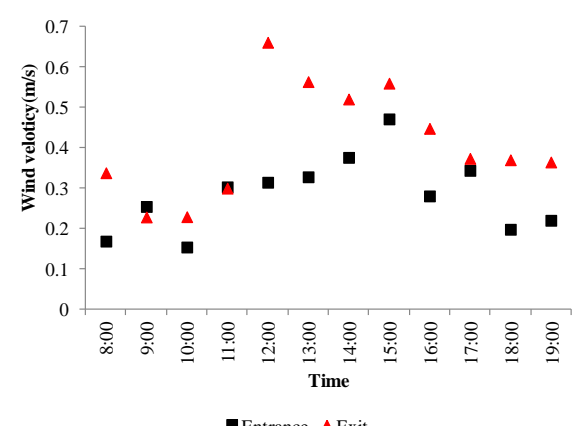

e) Indoor wind velocity on weekdays

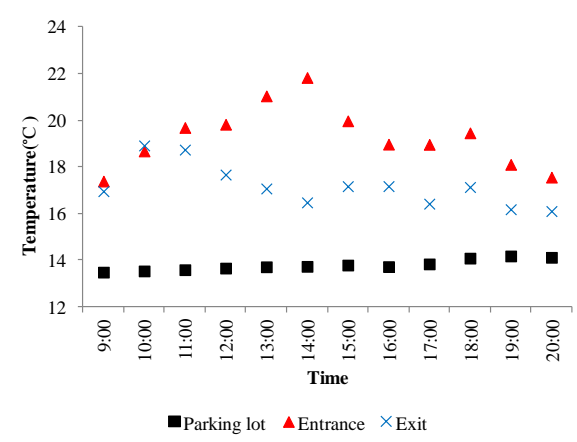

b) Indoor temperature during weekends

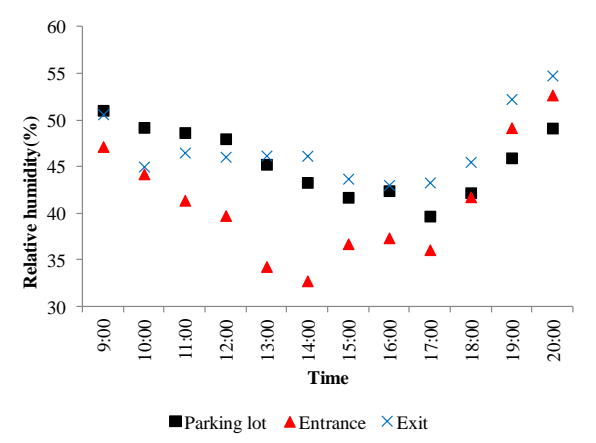

d) Indoor relative humidity on weekends

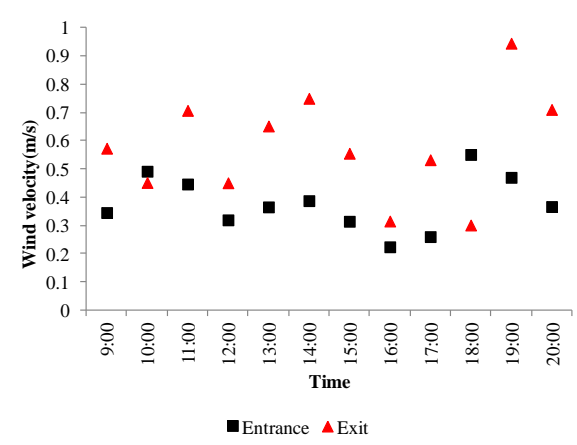

f) Indoor wind velocity on weekends

Figure 6. Hourly average of temperature, relative humidity, and wind velocity during the measurement period.

\subsection{Outdoor meteorological conditions}

Outdoor meteorological data at the meteorological station are given in Fig. 7. The outdoor temperatures shown in Fig. 7 fluctuated dramatically in the range of $10-40{ }^{\circ} \mathrm{C}$ because of seasonal transition from spring to summer. A slight increase in temperature was observed between the different measurement periods in the garage and in the surrounding outdoor area. Outdoor relative humidity also varied significantly from $20 \%$ to $90 \%$. An inverse relationship between temperature and relative humidity was also observed at the outdoor meteorological station, which was consistent with the indoor garage environment.

Natural wind during May and June in Harbin was indeed strong based on Fig. 7b. The majority of velocity measurements were no less than $2 \mathrm{~m} / \mathrm{s}$. Wind direction changed temporarily; however, the dominant direction might have been southerly. The data in Fig. 7 indicate that meteorological conditions during the garage measurement period showed no evident difference from the surrounding outdoor measurements. Comparison of PM1 number concentration between the garage and the surrounding outdoor environment was confirmed to be meaningful.

A wealth of literature has indicated that indoor-to-outdoor ratios are widely used indices reflecting the relationship between indoor and outdoor environments (Chow et al., 1996; Gouriou et al., 2004; Braniš et al., 2009). Indoor and outdoor ratios of temperature, relatively humidity and wind velocity were examined, and are listed in Fig. 8. 


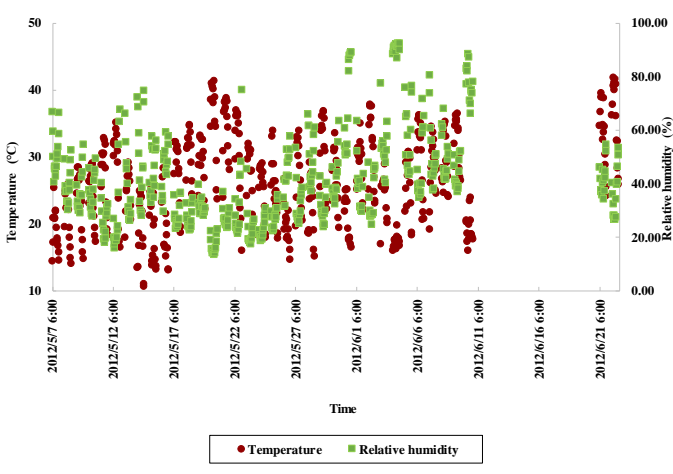

(a)

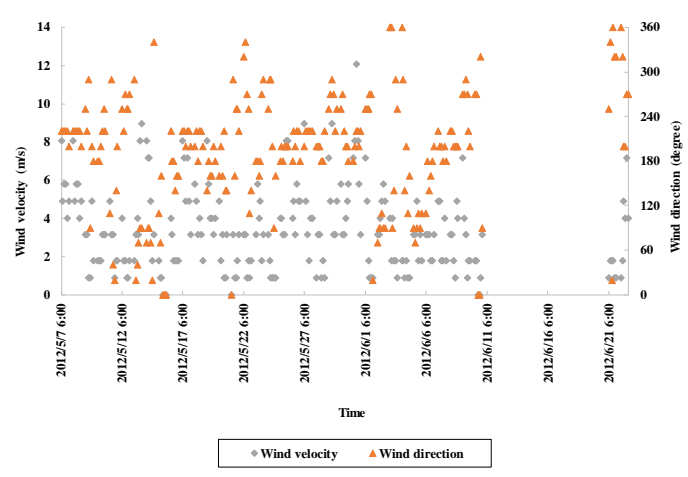

(b)

Figure 7. Meteorological data from the stations during the garage measurement period (7 May to 10 June) and surrounding outdoor measurement (21-22 June)

Because of the frequent fluctuation of outdoor meteorological conditions, although the thermal environment in the garage was relatively stable, variation of indoor-to-outdoor ratios were apparent in the range of 0.5-1.3 for temperature, $0.9-2.2$ for relative humidity, and less than 0.8 for wind velocity. Mean indoor-to-outdoor ratios of temperature and relative humidity were almost 0.7 and 1.2 , respectively.

These results demonstrate again that the underground facilities are slightly warmer and wetter than outdoors, as

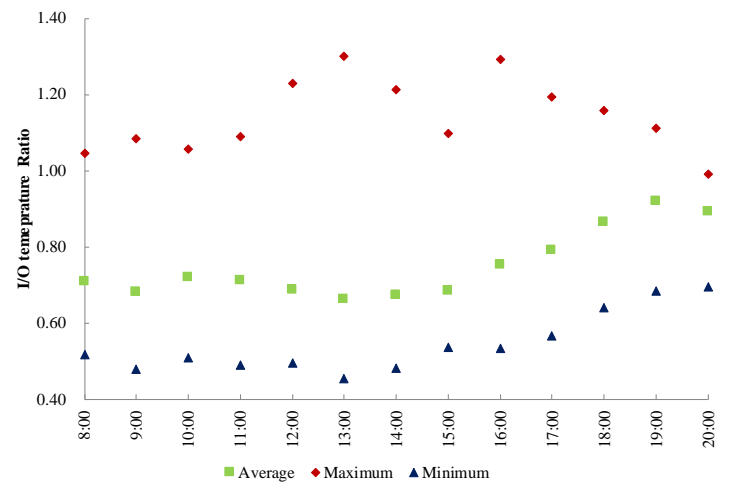

(a) Temperature indicated in previous studies (Gouriou et al., 2004; Li and Xiang, 2013; Zhu et al., 2014). In contrast, mean indoor-tooutdoor ratio of wind velocity was 0.2 , much lower than those for temperature and relatively humidity. This result may indicate that the structure of the entrance and exit (Fig. 1) that was effective at sheltering the garage from wind. This low indoor-to-outdoor ratio for wind velocity indicate that outdoor particles may not be a main source for particles inside the garage.

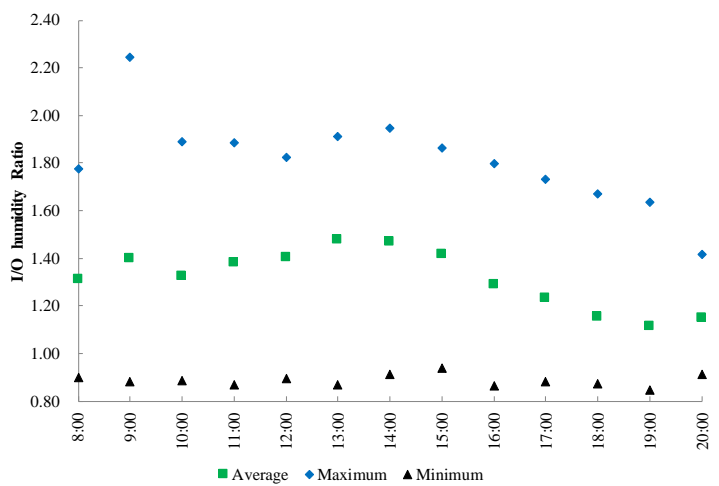

(b) Relative humidity

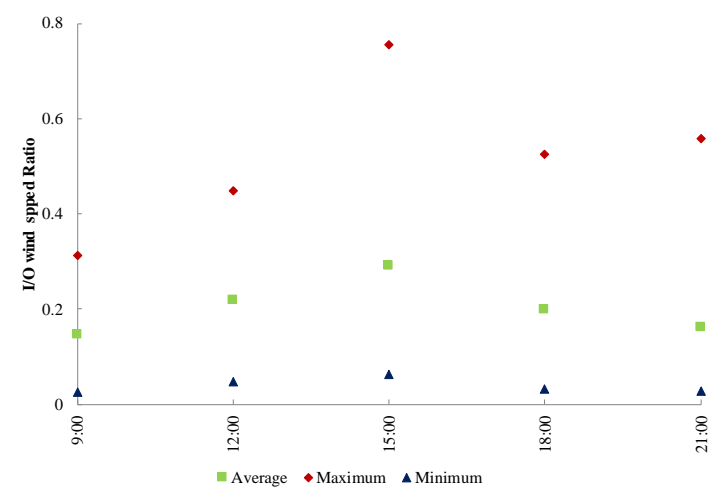

c) Wind velocity

Figure 8. Indoor and outdoor ratio of each parameter during the garage measurement period (7 May to 10 June). 


\subsection{PM1 number concentration}

The variation distribution of PM1 number concentration during the entire measurement period was uniform with a median of 19,290 particles $\mathrm{cm}^{-3}$ and a mean of 21,905 particles $\mathrm{cm}^{-3}$ for the garage, and a median of 16,604 particles $\mathrm{cm}^{-3}$ and a mean of 18,304 particles $\mathrm{cm}^{-3}$ outdoor. The hourly average PM1 number concentrations in the garage are presented in Fig. 9. Hourly variation presented a single peak at 9:00 in weekdays. The fluctuation of PM1 number concentration on weekends was weak compared with weekdays, and the difference between the maximum and minimum values was 10,007 particles $\mathrm{cm}^{-3}$. The hourly nanoparticle number concentration was higher during the majority of weekdays compared with weekends. The mean hourly nanoparticle number concentration on weekdays was 24,319 particles $\mathrm{cm}^{-3}, 1.44$ times higher than that on weekends $\left(16,924\right.$ particles $\left.\mathrm{cm}^{-3}\right)$. Based on statistical analysis, traffic flow, temperature in the garage, and wind velocity at the entrance/exit were the three main factors that influenced variation of PM1 number concentration on both weekdays and weekends, and increased traffic flow and decreased temperature and wind velocity led to increased PM1 number concentration. As shown in Fig. 5, mean traffic flow during weekdays was higher than the corresponding values during weekends, and mean temperature in the garage and wind velocity at entrance/exit on weekdays were lower than the corresponding values on weekends. This finding may result in higher PM1 number concentration on weekdays than on weekends.

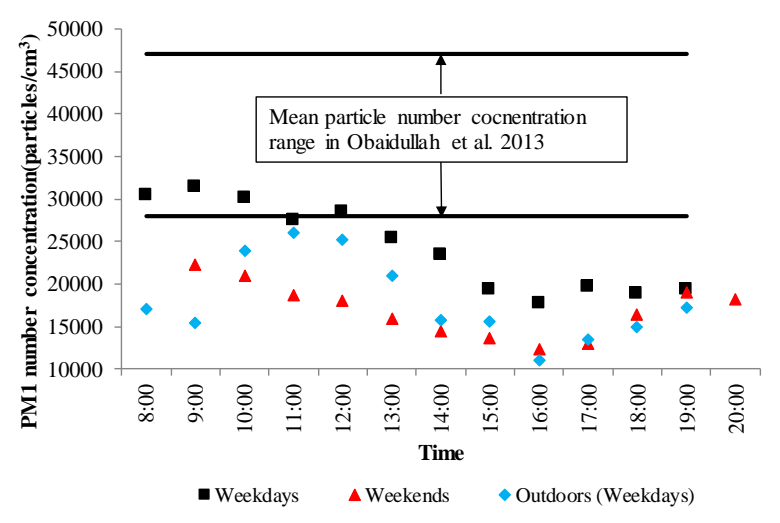

Figure 9. Hourly average of PM1 number concentration in the garage and outdoors during the measurement period.

The PM1 number concentrations of the underground garage and the outdoor environment were compared in this study. As shown in Fig. 10, the majority of measured PM1 number concentrations in the garage were higher than the corresponding data for the outdoor environment during the measurement period. The ratio between hourly mean PM1 number concentration in the garage and in the outdoor environment ranged from 1.06 to 2.03, which indicates that particulate pollution in the enclosed garage was more severe than that in the outdoor environment. High levels of particles emitted by vehicles and the enclosed environment that limited particle dispersion may have caused the elevated levels of particulate pollution in the garage.

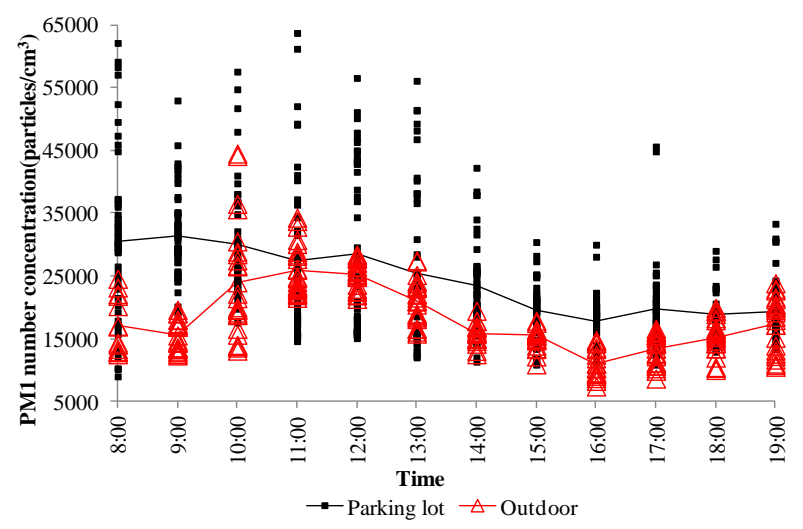

Figure 10. Comparison of PM1 number concentration between the garage and the outdoor environment. Black line and red line represent hourly mean nanoparticle number concentration in the garage and in the outdoor environment, respectively.

Because few studies have focused on particle number concentration in garages, the results of this study were compared only with those of Obaidullah et al., (2013), who measured particle number concentrations in three commercial garages in Belgium, with natural ventilation only and with both natural and mechanical ventilation. The temperature in those garages was within the range of 13$16{ }^{\circ} \mathrm{C}$, which was similar to that in our study. Although the thermal environment was nearly the same between the two studies, the data shown in Fig. 9 indicate that the particle number concentration reported by Obaidullah et al., (2013) was within the range of 28,000-47,000 particles $\mathrm{cm}^{-3}$, almost 1.15-2.8 times higher than that in our study. The difference between the two studies may be attributed to a higher traffic flow rate in the commercial garages, as has been confirmed in our previous study (Zhao and Zhao, 2013). More particles emitted from vehicles in the garage may contribute to a higher particle pollution level in the study by Obaidullah et al., (2013). Unfortunately, traffic flow rate was not reported by Obaidullah et al., (2013), and further comparison could not be conducted between the two studies.

\subsection{Impacts of traffic flow and the indoor thermal environment}

Fig. 11 shows Pearson and partial correlations between each parameter and PM1 number concentration during the entire measurement period. Detailed information on the correlation results can be found in Table S1 in the Supporting Information. The linear correlations between independent variables and PM1 number concentrations for the entire measurement period were relatively weak at the $5 \%$ level during measurement, with $0.1<|r|<0.5$. These results indicate that the relationships between PM1 number concentration and other measured variables were very complex and could not be simply represented as linear correlations. Hourly traffic flow, temperature in the garage, 
and wind velocity at the entrance/exit may be the main factors influencing PM1 number concentration. Pearson correlation analysis indicated that temperature in the garage was most strongly correlated with PM1 number concentration ( $r=-0.52)$, and traffic flow became the most important factor influencing PM1 number concentration ( $r=0.385)$ according to partial correlation analysis. The observations reflected that variation of PM1 number concentration was quite complex and was affected by traffic flow and the thermal environment simultaneously. Increase in traffic flow and decrease in temperature in the parking lot may result in increased PM1 number concentration. The relationship between wind velocity at the entrance/exit and PM1 number concentration during the entire measurement period was weak compared with that with traffic flow and temperature in the garage, with $r=-0.34$ for Pearson correlation and $r=-0.163$ for partial correlation. An inverse relationship was observed between wind velocity and PM1 number concentration.

The impacts of relative humidity in the garage and temperature and relative humidity at the entrance/exit on PM1 number concentration were less than those of traffic flow, temperature in the garage, and wind velocity, with $0.14<|r|<0.22$ for Pearson correlation and $0.025<|r|<0.154$ for partial correlation. Temperature at the entrance/exit had a negative correlation with PM1 number concentration based on Pearson correlation analysis. Weaker correlation between temperature at the entrance/exit $(r=0.025)$ and PM1 number concentration were observed from partial correlation analysis. These results illustrated that linear correlation between relative humidity in the garage, the thermal environment at the entrance/exit, and PM1 number concentration was weak and unstable.

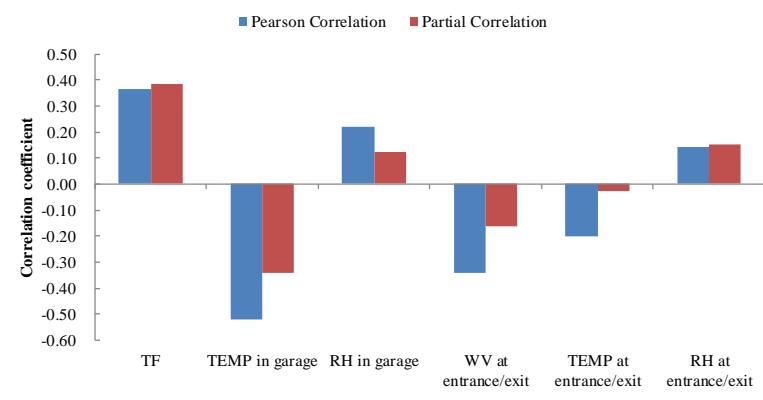

Figure 11. Pearson and partial correlations between each parameter and nanoparticle number concentration. TF, TEMP, RH, and WV represent traffic flow, temperature, relative humidity, and wind velocity, respectively.

\section{Conclusion}

Hourly mean traffic flow and nanoparticle number concentration in the garage were 0.2 vehicles/min and 21,905 particles $\mathrm{cm}^{-3}$, respectively. The traffic flow rate in the residential underground garage was almost $1 \%$ of the traffic flow in streets. PM1 number concentration was approximately 1.54 times higher than that in the surrounding outdoor environment. The thermal environment was quite stable in the garage with less than
$0.5{ }^{\circ} \mathrm{C}$ and $5 \%$ difference between mean and median for temperature and relative humidity, respectively. Wind velocity at the entrance/exit showed a random distribution with median of $0.11 \mathrm{~m} \mathrm{~s}^{-1}$ and mean of $0.22 \mathrm{~m} \mathrm{~s}^{-1}$. The mean indoor and outdoor ratios of temperature, relative humidity, and wind velocity were almost $0.7,1.2$, and 0.2 , respectively.

Hourly variation of PM1 number concentration was very complex based on the results of correlation analysis. Traffic flow, temperature in the garage, and wind velocity at the entrance/exit influenced PM1 number concentration simultaneously. The results also revealed that relative humidity in the garage, as well as temperature and relative humidity at the entrance/exit, had little and unstable effect on PM1 number concentration. Linear correlation could not be simply applied to evaluate the variation characteristic of PM1 number concentration in the garage.

Traffic flow had the most important impact on PM1 number concentration in the garage based on partial correlation analysis. Increase in traffic flow was associated with increase in PM1 number concentration. Temperature in the garage may be the second most dominant factor influencing PM1 number concentration variation in the entire measurement period. An inverse relationship between PM1 number concentration and temperature in the garage was observed. This observation may be attributed to increase in nuclei-mode particles under lowtemperature conditions. PM1 number concentration has a negative relationship with wind velocity at the entrance/exit, based on the correlation analysis. The results indicate that particle dilution caused by natural wind is one of the most important ways to reduce particle pollution in the parking garage.

The results of this study, especially the variation tendency of PM1 number concentrations with temperature in the underground garage, are in accordance with some on-road field studies (Jamriska et al., 2008; Olivares et al., 2007; Weichenthal et al., 2008; Tai et al., 2010). In general, this study provides an attempt to evaluate PM1 number concentration variation with traffic flow and the thermal environment. Further field measurements and laboratory research on the characteristics of nanoparticles will be conducted in a future study.

\section{Acknowledgements}

This work was supported by "the Fundamental Research Funds for the Central Universities" (grant number: DUT16RC(3)039) and China Postdoctoral Science Foundation funded project (grant number: 2016M601310). The authors wish to acknowledge Mingquan Yang, Yan Wang, and Haotong Shen of the School of Municipal and Environmental Engineering, Harbin Institute of Technology in China for helping with the field measurement work.

\section{References}

Braniš M., Šafránek J. and Hytychová A. (2009), Exposure of children to airborne particulate matter of different size fractions during indoor physical education at school, Building and Environment, 44, 1246-1252. 
Breiman L., Friedman J.H., Olshen R.A. and Stone C.G. (1984), Classification and Regression Trees, Wadsworth International Group, Belmont.

Bukowiecki N., Kittelson D.B., Watts W.F., Burtscher H., Weingartner E. and Baltensperger U. (2002), Real-time characterization of ultrafine and accumulation mode particles in ambient combustion aerosols, Journal of Aerosol Science, 33, 1139-1154.

Buonanno G., Marks G.B. and Morawska L. (2013), Health effects of daily airborne particle dose in children: Direct association between personal dose and respiratory health effects, Environmental Pollution, 180, 246-250.

Burtscher H. (2005), Physical characterization of particulate emissions from diesel engines: a review, Journal of Aerosol Science, 36, 896-932.

Charron A. and Harrison R.M. (2003), Primary particle formation from vehicle emissions during exhaust dilution in the roadside atmosphere, Atmospheric Environment, 37, 4109-4119.

Chen P., Bi X., Zhang J., Wu J. and Feng Y. (2015), Assessment of heavy metal pollution characteristics and human health risk of exposure to ambient $\mathrm{PM}_{2.5}$ in Tianjin, China, Particuology, 20, 104-109.

Chow W.K., Wong L.T. and Fung W.Y. (1996), Field Study on the Indoor Thermal Environment and Carbon Monoxide Levels in a Large Underground Car Park, Tunnelling and Underground Space Technology, 11, 333-343.

Franck U., Odeh S., Wiedensohler A., Wehner B. and Herbarth O. (2011), The effect of particle size on cardiovascular disorders - the smaller the worse, Science of the Total Environment, 409, 4217-4221.

Gidhagen L., Johansson C., Langner J. and Foltescu V.L. (2005), Urban scale modeling of particle number concentration in Stockholm, Atmospheric Environment, 39, 1711-1725.

Gouriou F., Morin J.P. and Weill M.E. (2004), On-road measurements of particle number concentrations and size distributions in urban and tunnel environments, Atmospheric Environment, 38, 2831-2840.

Guilford J.P. and Fruchter B. (1973), Fundamental statistics in psychology and education, McGraw-Hill Kogakusha, Ltd, Tokyo.

Hinds W.C. (1982), Aerosol technology, John Wiley \& Sons Inc, New York.

Jamriska M., Morawska L. and Mergersen K. (2008), The effect of temperature and humidity on size segregated traffic exhaust particle emissions, Atmospheric Environment, 42, 2369-2382.

Janhäll S., Molnar P. and Hallquist M. (2012), Traffic emission factors of ultrafine particles: effects from ambient air, Journal of Environmental Monitoring, 14, 2488-2496.

Kittelson D.B., Watts W.F., Johnson J.P., Schauer J.J. and Lawson D.R. (2006), On-road and laboratory evaluation of combustion aerosols-Part 2: Summary of spark ignition engine results, Journal of Aerosol Science, 37, 931-949.

Kristensson A., Johansson C., Westerholm R., Swietlicki E., Gidhagen L., Wideqvist U. and Vesely V. (2004), Real-world traffic emission factors of gases and particles measured in a road tunnel in Stockholm, Sweden, Atmospheric Environment, 38, 657-673.

Li Y.X. and Xiang R.B. (2013), Particulate pollution in an underground car park in Wuhan, China, Particuology, 11, 9498.
Maricq M.M. (2007), Chemical characterization of particulate emissions from diesel engines: A review, Journal of Aerosol Science, 38, 1079-1118.

Maricq M.M., Podsiadlik D. and Chase R. (1999), Gasoline Vehicle Particle Size Distributions: Comparison of Steady State, FTP, and US06 Measurements, Environmental Science \& Technology, 33, 2007-2015.

McGregor F., Ferreira L. and Morawska L. (2003), Modelling of sub-micrometer particle concentrations in free-flowing freeway traffic, Brisbane, Australia: some empirical results, Transport Research Part D: Transport and Environment, 8, 229-241.

Nicolai T., Carr D., Weiland S.K., Duhme H., Von E.O., Wagner C. and Von M.E. (2003), Urban traffic and pollutant exposure related to respiratory outcomes and atopy in a large sample of children, European Respiratory Journal, 21, 956-963.

Obaidullah M., Dyakov I.V., Peeters L., Bram S. and De Ruyck J. (2013), Comparison of particle emissions from enclosed parking garages and streets, Global NEST Journal, 15, 457-465.

Olivares G., Johansson C., Strom J. and Hansson H.C. (2007), The role of ambient temperature for particle number concentrations in a street canyon, Atmospheric Environment, 41, 2145-2155.

Pekkanen J., Timonen K.L., Ruuskanen J., Reponen A. and Mirme A. (1997), Effects of ultrafine and fine particles in urban air on peak expiratory flow among children with asthmatic symptoms, Environmental Research, 74, 24-33.

Penttinen P., Timonen K.L., Tiittanen P., Mirme A., Ruuskanen J. and Pekkanen J. (2001), Ultrafine particles in urban air and respiratory health among adult asthmatics, European Respiratory Journal, 17, 428-435.

Peters A., Klot S.V., Heier M., Trentinaglia I., Hörmann A., Erich W.H. and Löwel H. (2004), Exposure to Traffic and the Onset of Myocardial Infarction, The New England Journal of Medicine, 351, 1721-1730.

Pfeifer G.D., Harrison R.M. and Lynam D.R. (1999), Personal exposures to airborne metals in London taxi drivers and office workers in 1995 and 1996, Science of the Total Environment, 235, 253-260.

Pui D.Y.H., Chen S.C., and Zuo, Z. (2014), PM 2.5 in China: Measurements, sources, visibility and health effects, and mitigation, Particuology, 13, 1-26.

Sitzmann B., Kendall M., Watt J. and Williams I. (1999), Characterisation of airborne particles in London by computercontrolled scanning electron microscopy, Science of the Total Environment, 241, 63-73.

Tai A.P.K., Mickley L.J. and Jacob D.J. (2010), Correlations between fine particulate matter $\left(\mathrm{PM}_{2.5}\right)$ and meteorological variables in the United States: Implications for the sensitivity of $\mathrm{PM}_{2.5}$ to climate change, Atmospheric Environment, 44, 3976-3984.

Tan Z.C. and Tay, R. (2008), Sources contributing to PM2.5 in a commercial truck cabin in winter, Transport Research Part D: Transport and Environment, 13, 54-58.

Vogt W.P. and Johnson B. (2012), Correlation and Regression Analysis, SAGE Publications, California.

Von K.S., Wölke G., Tuch T., Heinrich J., Dockery D.W., Schwartz J., Kreyling W.G. Wichmann H.E. and Peters A. (2002), Increased asthma medication use in association with ambient fine and ultrafine particles, European Respiratory Journal, 20, 691-702.

Wang X. and Gao H.O. (2011), Exposure to fine particle mass and number concentrations in urban transportation 
environments of New York City, Transport Research Part D: Transport and Environment, 16, 384-391.

Weichenthal S. (2012), Selected physiological effects of ultrafine particles in acute cardiovascular morbidity, Environmental Research, 115, 23-36.

Weichenthal S., Dufresne A., Rivard C.I. and Joseph L. (2008), Determinants of ultrafine particle exposures in transportation environments: findings of an 8-month survey conducted in Montreal, Canada, Journal of Exposure Science and Environmental Epidemiology, 18, 551-563.

Xue H. and Ho J.C. (2000), Modelling of Heat and Carbon Monoxide Emitted from Moving Cars in an Underground Car Park, Tunnelling and Underground Space Technology, 15, 101115.

Zhang Y.W., Gu Z.L., Cheng Y., Shen Z.X., Dong J.G. and Lee S.C. (2012), Measurement of diurnal variations of PM2.5 mass concentrations and factors affecting pollutant dispersion in urban street canyons under weak-wind conditions in Xian, Aerosol and Air Quality Research, 12, 1261-1268.

Zhao Y. and Zhao J.N. (2013), Field Study on PM1 Air Pollution in a Residential Underground Parking Lot, In: Proceedings of the 8th International Symposium on Heating, Ventilation and Air Conditioning, Li A., Zhu Y. and Li Y. (Eds.), Springer Berlin Heidelberg, Germany.

Zhu C., Li J.G., Wang L., Morawska L., Zhang X. and Zhang Y.L. (2014), Size-resolved particle distribution and gaseous concentrations by real-world road tunnel measurement, Indoor and Built Environment, 23, 225-235. 